\title{
Correction to: An analytic perspective on panpsychism
}

\section{Godehard Brüntrup and Ludwig Jaskolla (eds.): Panpsychism:} contemporary perspectives. Oxford University Press, 2017, 426 pp., ISBN: $9780199359943, \$ 74.00 \mathrm{HB}$

\section{Gregory Michael Nixon ${ }^{1}$}

\section{Correction to: Metascience (2017) 26:471-474 https://doi.org/10.1007/s11016-017-0225-7}

In the November issue of 2017, in a review of the book Panpsychism: contemporary perspectives, one of the authors' names was misspelled. Godehard Brüntrup's name was spelled incorrectly as Brüntrip.

The original article can be found online at https://doi.org/10.1007/s11016-017-0225-7.

Gregory Michael Nixon

doknyx@telus.net

1 University of Northern British Columbia, Prince George, BC, Canada 